Louisiana State University

LSU Digital Commons

Faculty Publications

Department of Biological Sciences

$11-1-2006$

\title{
A molecular phylogenetic analysis of strombid gastropod morphological diversity
}

Jared M. Latiolais

Louisiana State University

Michael S. Taylor

Louisiana State University

Kaustuv Roy

Division of Biological Sciences

Michael E. Hellberg

Louisiana State University

Follow this and additional works at: https://digitalcommons.Isu.edu/biosci_pubs

\section{Recommended Citation}

Latiolais, J., Taylor, M., Roy, K., \& Hellberg, M. (2006). A molecular phylogenetic analysis of strombid gastropod morphological diversity. Molecular Phylogenetics and Evolution, 41 (2), 436-444.

https://doi.org/10.1016/j.ympev.2006.05.027

This Article is brought to you for free and open access by the Department of Biological Sciences at LSU Digital Commons. It has been accepted for inclusion in Faculty Publications by an authorized administrator of LSU Digital Commons. For more information, please contact ir@lsu.edu. 


\title{
A molecular phylogenetic analysis of strombid gastropod morphological diversity
}

\author{
Jared M. Latiolais ${ }^{\text {a }}$, Michael S. Taylor ${ }^{\text {a,b }}$, Kaustuv Roy ${ }^{\mathrm{c}, 1}$, Michael E. Hellberg ${ }^{\mathrm{a}, *, 1}$ \\ ${ }^{a}$ Department of Biological Sciences, Louisiana State University, Baton Rouge, LA 70803, USA \\ ${ }^{\mathrm{b}}$ Department of Biological Sciences, Univ of Notre Dame, Notre Dame, IN 46556-0369, USA \\ ${ }^{c}$ Section of Ecology, Behavior and Evolution, Division of Biological Sciences, University of California, San Diego, \\ 9500 Gilman Drive, La Jolla, CA 92093-0116, USA
}

Received 9 February 2006; revised 19 May 2006; accepted 24 May 2006

Available online 3 June 2006

\begin{abstract}
The shells of strombid gastropods show a wide variety of forms, ranging from small and fusiform to large and elaborately ornamented with a strongly flared outer lip. Here, we present the first species-level molecular phylogeny for strombids and use the resulting phylogenetic framework to explore relationships between species richness and morphological diversity. We use portions of one nuclear ( 325 bp of histone H3) and one mitochondrial (640 bp of cytochrome oxidase I, COI) gene to infer relationships within the two most species-rich genera in the Strombidae: Strombus and Lambis. We include 32 species of Strombus, representing 10 of 11 extant subgenera, and 3 of the 9 species of Lambis, representing 2 of 3 extant subgenera. Maximum likelihood and Bayesian analyses of COI and of H3 and COI combined suggest Lambis is nested within a paraphyletic Strombus. Eastern Pacific and western Atlantic species of Strombus form a relatively recent monophyletic radiation within an older, paraphyletic Indo-West Pacific grade. Morphological diversity of subclades scales positively with species richness but does not show evidence of strong phylogenetic constraints.
\end{abstract}

(C) 2006 Elsevier Inc. All rights reserved.

Keywords: Morphospace; Shell shape; Cytochrome oxidase I; Histone H3; Strombus; Lambis

\section{Introduction}

Biological diversity can be measured in ways ranging from simple counts of species or higher taxa to quantitative measures of morphological, functional or phylogenetic diversity (Harper and Hawksworth, 1994; Purvis and Hector, 2000), but the relationships between various measures of biodiversity remain poorly known. Morphological diversity is one of the more intuitive measures of biodiversity (Williams et al., 1994), but richness of species or higher taxa can be a poor predictor of morphological diversity, both for living biota as well as for extinct taxa (Foote, 1995, 1997; Roy and Foote, 1997; Roy et al., 2001; McClain et al.,

\footnotetext{
* Corresponding author. Fax: +1 2255782597.

E-mail address: mhellbe@1su.edu (M.E. Hellberg).

1 These authors contributed equally to this work.
}

2004). To date, studies of morphological diversity patterns in a phylogenetic framework have focused on vertebrates (Hulsey and Wainwright, 2002; Harmon et al., 2003; Ricklefs, 2004, 2005), freshwater mollusks (Wilson et al., 2004) or fossil taxa (e.g., Wagner, 1995, 1996); such analyses are lacking for living marine invertebrates.

The morphological variation seen within the marine gastropod family Strombidae (conchs and their kin) make them fine candidates for examining how morphological diversity scales with species richness. All strombids exhibit determinate shell growth (Abbott, 1960; Vermeij and Signor, 1992), providing an unambiguous gauge of adult size and shape. The two most species-rich of traditionally defined strombid genera are Lambis Röding 1798 and Strombus Linné 1758 (Abbott, 1960, 1961). Species in both of these genera are herbivores associated with shallowwater reefs and grass beds. Both possess similar soft tissue 
anatomies, egg masses, and radulae (Abbott, 1961), which led Kronenberg (1998) to suggest that Lambis and Strombus belong together in a group within the Strombidae, even though their shells show striking morphological differences (Fig. 1). In a previous study, Roy et al. (2001) examined the relationship between spatial patterns of morphological diversity and species richness in Strombus and Lambis but, because of the lack of a well-supported phylogeny, could not examine how species richness of individual clades of strombid gastropods related to their morphological diversity.

The last major taxonomic revisions of Strombus and Lambis were undertaken almost half a century ago (Abbott, 1960, 1961). Since then, some subspecies have been elevated to species status (e.g., Mienis, 1971; Kronenberg and Vermeij, 2002), subgenera have been raised to genera (e.g., Kronenberg, 1998), putative species have been revealed as hybrids (Kronenberg, 1993, 1999), and species have been carved from existing genera to create new monotypic genera (e.g., Mirabilistrombus, Kronenberg, 1998; Tridentarius, Kronenberg and Vermeij, 2002). Few studies, however, have addressed relationships among subgenera (sensu Abbott). Stone (2001) explored relationships among nine species of Lambis and three Strombus outgroups using morphological characters. One Lambis species (L. crocata) fell among the outgroups, suggesting that Lambis was paraphyletic and Strombus was polyphyletic, although bootstrap support values for all relationships were too low $(<40 \%)$ for any robust conclusions. At a higher taxonomic level, Kronenberg and Vermeij (2002) recognized a shell character (glazing of the outer lip) shared by all Neotropical species as well as some Indo-Pacific (sub)genera, including Euprotomus and Tridentatus. Kronenberg and Vermeij (2002) also agreed with Stone (2001) that Lambis and Strombus sensu lato (s.l.) were polyphyletic or paraphyletic.

Here, we use DNA sequences from two protein-coding gene regions, one mitochondrial (cytochrome oxidase subunit I, COI) and one nuclear (histone subunit 3, H3), to infer molecular phylogenetic relationships among species and superspecific taxa within Lambis and Strombus. We then use this molecular phylogeny in conjunction with quantitative measures of shell shape to examine the relationship between taxonomic and morphological diversity within this group. We also assess whether the strombids of the New World are a monophyletic radiation, or a polyphyletic assemblage of species collected from a more ancient and species-rich Indo-West Pacific fauna.

\section{Materials and methods}

\subsection{Selection of taxa}

This study includes 31 species of Strombus, representing 10 of the 11 extant subgenera of Abbott (1960), and 3 of the 9 species of Lambis representing 2 of the 3 extant subgenera (Supplementary material Table 1). Our taxon sampling is nearly complete for the Eastern Pacific and Western Atlantic regions (lacking only the Brazilian $S$. goliath of 12 species in total), but less so for the Indo-Pacific. Like most other invertebrate groups, the total number of Indo-Pacific species belonging to Strombidae is currently unknown but our sample of 23 species represents about a third of the 72 named species and subspecies of Abbott $(1960,1961)$. However, because our study includes representatives from nearly all traditionally defined subgenera (sensu Abbott, 1960, 1961) of Strombus and Lambis, the resulting phylogeny should reflect the relationships among the main lineages within Strombidae.

\subsection{DNA extraction, amplification, and sequencing}

Genomic DNA was extracted using protocols that varied with the quality and age of samples (see Supplementary material Table 1 for collection information). For well preserved museum samples and for fresh tissue, we used a modified cetyltrimethylammonium bromide (CTAB) extraction, followed by phenol/chloroform extraction and alcohol precipitation protocol (Toonen, 1997). When this approach failed (usually for older museum samples), a modified version (Chase et al., 1998) of the QIAmp DNA

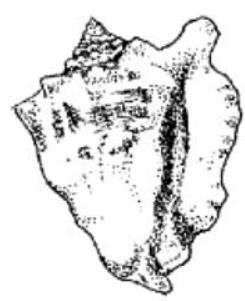

Strombus raninus



Strombus taurus



Lambis lambis

Fig. 1. Shell morphologies for three strombid species. Strombus raninus is a Caribbean species placed by Abbott (1960) in the subgenus Tricornis. Strombus taurus, also in Tricornis, is found in the Marshall and Marianas Islands of the central Pacific. Lambis lambis ranges from eastern Africa to the central Pacific. Illustrations by Ben Anders. 
extraction kit (QIAGEN, Chatsworth, CA, USA) was used. Most of our samples were collected fresh or came from recent ( $<5$ years post-collection) museum specimens, but we had success with one sample (S. canarium, ANSP 104315) preserved in ethanol for over 90 years (collected in 1910).

We used 1-2 $\mu \mathrm{L}$ of DNA from each genomic extraction as template for amplification via the polymerase chain reaction (PCR). All reactions were carried out at $50 \mu \mathrm{L}$ volumes in a PTC-100 or PTC-200 thermal cycler (MJ Research, Inc, Watertown, MA) under the following conditions: a hot start of $94^{\circ} \mathrm{C}$, a first cycle of $94^{\circ} \mathrm{C}$ for $3 \mathrm{~min}, 50^{\circ} \mathrm{C}$ for $2 \mathrm{~min}$, and $72{ }^{\circ} \mathrm{C}$ for $2 \mathrm{~min}$, followed by 35 cycles of $94^{\circ} \mathrm{C}$ for $35 \mathrm{~s}, 50^{\circ} \mathrm{C}$ for $1 \mathrm{~min}$, and $72^{\circ} \mathrm{C}$ for $1 \mathrm{~min} 15 \mathrm{~s}$.

A $350 \mathrm{bp}$ region of $\mathrm{H} 3$ was amplified and sequenced using primers from Colgan et al. (1998) (H3A $=5^{\prime}$-ATG GCTCGTACCAAGCAGACVGC-3', H3B = 5' -ATATC CTTRGGCATRATRGTGAC-3'). A $710 \mathrm{bp}$ region of COI was amplified using the primers of Folmer et al. (1994) ( $\mathrm{LCO} 1=5^{\prime}$-CGTCAACAAATCATAAAGATATTGG-3', HCO1 $=5^{\prime}$-TAAACTTCAGGGTGACCAAAAAATCA-3' ). In reactions where sequencing across the full length of the COI fragment proved problematic, two internal primers were designed from aligned sequence obtained using the above primers $\left(\mathrm{LCO} 1731=5^{\prime}\right.$-AGCTCCTGATATRGCY TTYCC $-3^{\prime}, \mathrm{HCO} 2004=5^{\prime}$-CTCAAACTGTATDCCYCG YCAYC- $3^{\prime}$ ).

PCR reactions were visualized on $1 \%$ agarose gels. In those reactions producing a single band of the expected size, two or three amplicons per individual were pooled and cleaned using the Strataprep PCR Purification Kit (Stratagene, La Jolla, CA). Reactions producing multiple bands, or reactions that proved difficult to sequence directly, were gel excised, polished using Strategene's PCR Polishing Kit, and then cloned using Invitrogen's (Carlsbad, CA) Zero Blunt-II TOPO Cloning Kit. Plasmids containing inserts of the desired size were directly sequenced using M13f and M13r primers provided with the TOPO Cloning Kit. All products were sequenced in both directions using fluorescently labeled dye-terminators (ABI, Foster City, CA) on an ABI 377 DNA Sequencer at LSU's Museum of Natural Science. All sequences are available from GenBank (H3: DQ525242-DQ525277, COI: DQ525207-DQ525241).

\subsection{Phylogenetic analyses}

Six-hundred and forty basepairs of COI and $325 \mathrm{bp}$ of $\mathrm{H} 3$ were aligned by eye. No insertions or deletions were present in either marker, and both fragments remained in open reading frames over their total respective lengths. Aporrhais pespelecani, a member of the family Aporrhaidae, was used as the outgroup in our analysis because strombids and aporrhaids are generally thought to be closely related (Roy, 1996). In preliminary work we also examined sequences from other potential outgroups that have been placed in the Strombidae (Terebellum terebellum, Tibia fusus), but Aporrhais proved to be closer to the ingroup taxa than these other species.
To determine the DNA substitution models that most closely fit our data, each of the character sets (COI, H3, and combined) were analyzed in Modeltest (Posada and Crandall, 1998) and MrModeltest (Nylander, 2002) using hierarchical likelihood ratio tests (HLRTs, Huelsenbeck and Crandall, 1997) for several different variations of the data matrices. Both full data sets and truncated alternatives, shortened so that no missing characters were present, consistently yielded the same evolutionary models, so the full set (including missing characters for some taxa) was used in the analysis.

Phylogenetic trees were created in PAUP 4.0b10 (Swofford, 2001) for $\mathrm{H} 3(\operatorname{TrN}+\mathrm{I}+\Gamma)$ and COI $(\operatorname{TvM}+\mathrm{I}+\Gamma)$ separately, using a heuristic maximum likelihood (ML) search with five random additions of taxa under the TBR branch swapping option and bootstrapped using 100 replicates. An incongruence length difference test (implemented in PAUP as a partition homogeneity test) was performed on the resulting $\mathrm{H} 3$ and $\mathrm{COI}$ trees, which were found to be congruent $(p=0.99)$, justifying analysis of a combined data set (Cunningham, 1997). A phylogeny was derived from the combined data set under the HLRT model $(\mathrm{TvM}+\mathrm{I}+\Gamma)$ using a heuristic ML search with five random additions of taxa and the TBR branch swapping option. The results from this search were bootstrapped using 100 replicates. For an alternative measure of topological support, a Bayesian analysis (using GTR $+\mathrm{I}+\Gamma$ ) was performed on the $\mathrm{H} 3$, COI, and combined data set using MrBayes 3.04 (Huelsenbeck and Ronquist, 2001). Each data set was run independently five times for 1.2 million generations per run, with parameter values and trees saved once every 100 generations. The estimated parameters for each run were graphed to assess parameter stationarity (Leaché and Reeder, 2002) and to determine the appropriate number of generations to exclude for burn-in. The first 600,000 generations (COI) or 800,000 generation (H3 and combined) were excluded, as this many iterations were required for all parameters to reach stationarity (data not shown); transition rates required over 20 times as many generations to do so as did likelihood scores. The remaining trees from all five runs were imported into PAUP where majority rule consensus trees were created (spanning 3 million generations for COI, 2 million for $\mathrm{H} 3$ and combined).

\subsection{Morphospace analyses}

We used shell shape, a complex trait with considerable functional significance (Vermeij, 1978, 1987; Savazzi, 1991), to compute morphological diversity metrics. We used the same method and specimens as Roy et al. (2001) to quantify morphological diversity, except the present study uses only 32 species ( $S$. latus and $S$. wilsoni, which were not included in the initial analysis, were excluded here) represented in the molecular phylogeny to define the strombid morphospace. Briefly, we used Elliptical Fourier (EFA) analyses and computed 10 harmonics for each specimen using digitized shell outline and available 
software (Rohlf and Ferson, 1992; Isaev, 1995; Isaev and Denisova, 1995; see Roy et al., 2001 for details of methods). A principal components analysis (PCA) using the 10 harmonics was used to define the axes of a shape morphospace. As in Roy et al. (2001), we used two different measures of morphological diversity: (i) geometric mean of the ranges of scores on each of six PCA axes was used to measure the volume of morphospace occupation and (ii) the geometric mean of the variance of scores on each axis was used to measure the dispersion among taxa (Foote, 1997).

We tested whether the relationship between taxonomic and morphological diversity is constrained by the phylogenetic relationships by comparing the observed patterns against a null model. First we identified all subclades (defined as monophyletic groups supported in our combined phylogenetic analysis by Bayesian posterior probabilities of 0.85 or greater) and computed the morphological diversity of the subclade measured using the two metrics described above. We then compared the observed relationships between taxonomic richness and morphological diversity of subclades with the null expectations derived by computing the morphological diversities of randomly generated subclades (based on 1000 iterations) of the same richness levels.

\section{Results}

\section{1. $\mathrm{H3}$}

Of the 325 base pairs of $\mathrm{H} 3$ sequenced and aligned for all 36 species, 64 sites were variable and 45 sites were parsimony informative. Although $\mathrm{H} 3$ occurs in multiple copy histone clusters, these appear to undergo rapid concerted evolution (DeBry and Marzluff, 1994; Thatcher and Gorovsky, 1994; Rooney et al., 2002); we detected no signs of heterozygosity in any of the chromatographs for $\mathrm{H} 3$ sequences. The deepest well-supported node in the H3 tree (Supplementary material Fig. 1), with a maximum likelihood bootstrap (MLB) value of 79 and Bayesian posterior probability (BPP) of 99, unites a clade that includes all Eastern Pacific and Atlantic (EPA) species and some Indo-West Pacific (IWP) species (including all Lambis). Canarium, Labiostrombus, Laevistrombus, and Doxander fall into a poorly resolved paraphyletic IWP grade. The three Lambis species sampled occur in a monophyletic clade (MLB 52, BPP 97) as sister to two IWP Tricornis species (themselves monophyletic: MLB 80, BPP 100). The EPA strombids, which includes $S$. latus, the only species from the Eastern Atlantic, are monophyletic (MLB 71, BPP 99), with all EPA Tricornis falling into a single clade (MLB 61, BPP 97). Because the Indo-Pacific Tricornis are more closely related to Lambis than to EPA Tricornis, the subgenus Tricornis as defined by Abbott (1960) appears to be polyphyletic. The three Lentigo species do not appear monophyletic in the $\mathrm{H} 3$ tree either, although their polyphyly is not supported statistically.
The Bayesian $\mathrm{H} 3$ tree (not shown) places $S$. lentiginosis as sister to a clade of EPA + (Lambis and IWP Tricornis), again without support. Otherwise, topologies of the ML and Bayesian $\mathrm{H} 3$ trees are identical except for a few basal taxa for which resolution in the Bayesian analysis was 0.50 posterior probability.

\section{2. $\mathrm{COI}$}

Strombus (Lentigo) lentiginosus consistently failed to amplify for COI. For the 35 other species, 260 sites of the total 640 aligned base pairs of COI were variable and 229 bp were parsimony informative. The topology of the Bayesian COI tree was identical to that of the ML COI tree for all clades with $>0.50$ BPP support. Similar tree topologies were recovered by both ML (Supplementary material Fig. 2) and Bayesian methods (identical to the ML tree for all clades with $>0.50$ BPP support, not shown). The relatively rapid evolution of COI provides resolution at several terminal nodes. Strombus (sensu stricto) (MLB 98, BPP 100) and Euprotomus (MLB 99, BPP 100) are well supported as monophyletic subgenera. The ML tree again places EPA and IWP Tricornis in different clades, with the Neotropical Tricornis again supported as monophyletic (MLB 64, BPP 93). The genus Lambis is well supported as a monophyletic clade (MLB 91, BPP 100). The COI data statistically supported only one node that was in potential conflict with the H3 data: four Canarium species (S. maculatus, S. mutabilis, S. microurceus, and $S$. labiatus) supported as the sister clade to most other species sampled in the $\mathrm{H} 3$ tree (BPP 81) instead fall into a larger Canarium clade (MLB 72, BPP $100)$ in the COI tree.

\subsection{Combined $\mathrm{H} 3$ and $\mathrm{COI}$}

The congruency of the H3 and COI trees $(p=0.99)$ allowed these markers to be combined into a single analysis (Cunningham, 1997). The combined tree provides better resolution of overall topology than either $\mathrm{H} 3$ or COI separately (Fig. 2). As in the H3 tree and, to a lesser extent the COI tree, a deep node (MLB 78, BPP 96) splits the tree into a large clade containing all EPA and some IWP subgenera, and an unresolved paraphyletic group with subgenera found only in the Indo-West Pacific. The monophyletic IWP subgenus Euprotomus (MLB and BPP 100) is supported (MLB 70, BPP 98) as the sister to a monophyletic (MLB 98, BPP 100) EPA radiation. Lambis nests as a monophyletic group (MLB 99, BPP 100) inside Strombus (s.l.), with IWP Tricornis supported as a sister clade by a BPP of 93. As in the H3 and COI trees, Abbott's (1960) subgenus Tricornis is polyphyletic in the combined tree. Neotropical Tricornis are more closely related to Neotropical species from other subgenera, than to IWP Tricornis, which are closely allied to Lambis. The representatives of Lentigo also fall into different places on both the combined and $\mathrm{H} 3$ trees, although the 


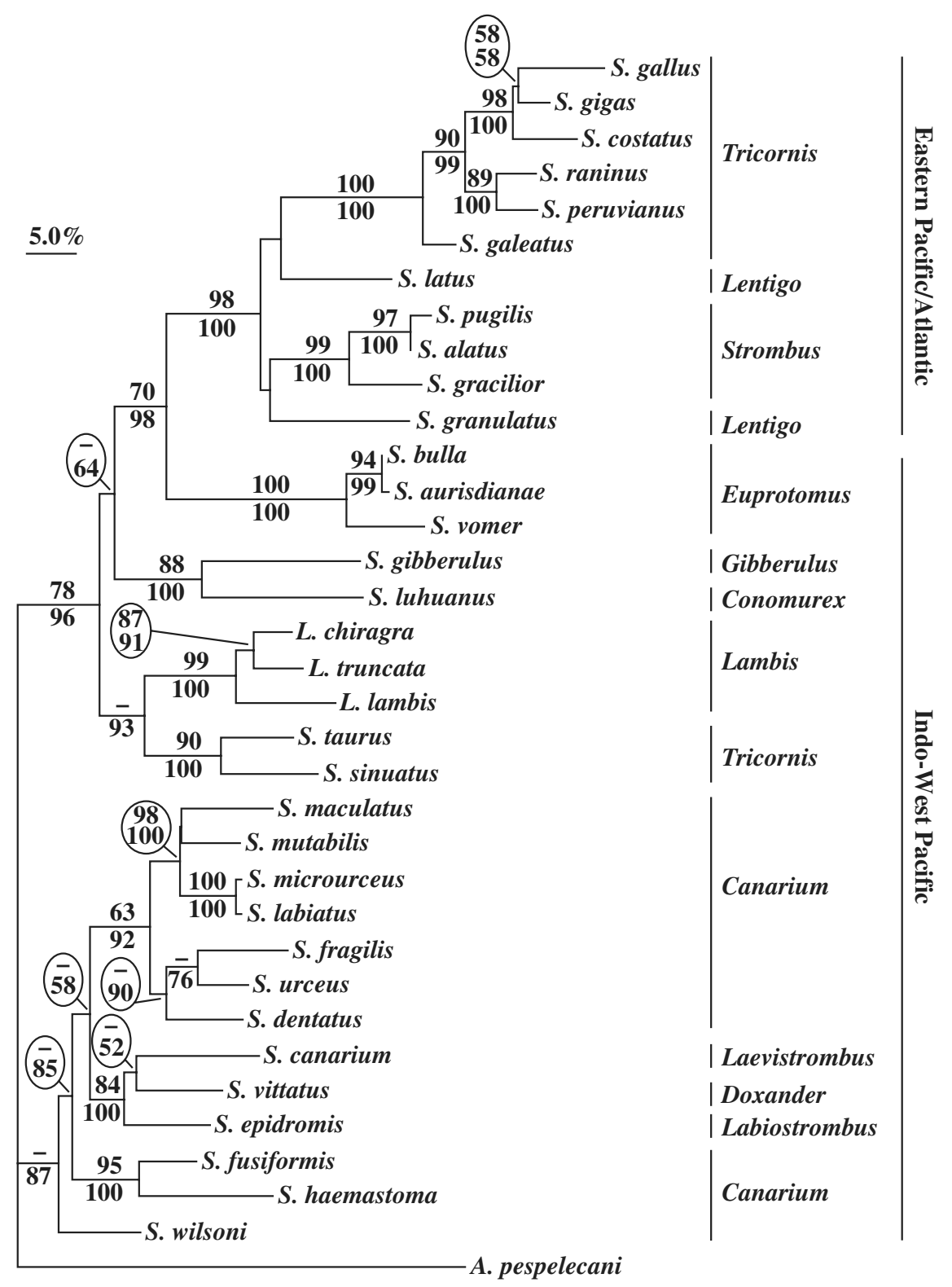

Fig. 2. Maximum likelihood (ML) tree constructed from a combined data set consisting of 325 bp H3 and 640 bp COI. ML bootstrap support (100 replicates) is given above corresponding branches, with Bayesian posterior probabilities $(\times 100)$ shown beneath.

COI tree places them together in an unsupported clade. Thus Lentigo, as proposed by Abbott (1960), may also be polyphyletic although additional data are required to resolve the relationship. The Bayesian combined tree had a topology nearly identical to that of the ML combined tree, differing only in the placement of $S$. latus and $S$. maculatus, neither of which has support in either analysis.

\subsection{Scaling of taxonomic and morphological diversity}

The first six principal components explained $89.6 \%$ of the variance in shell shape and we used these axes to calculate the morphological diversity metrics. Species traditionally assigned to the Strombus s.l. have very different shell shapes compared to those assigned to Lambis (Fig. 1) and these differences are reflected in their distributions in the morphospace defined here (Fig. 3). Both metrics of morphological diversity show a general increase with taxonomic richness (Fig. 4). The relationship between geometric mean of the range of PCA scores and species richness of subclades is stronger and more linear (Spearman Rho 0.720, $p=0.0007$ ) than that between the geometric mean of variance of PCA scores and richness (Spearman Rho 0.456, $p=0.04$ ). Comparisons of the observed relationships between the taxonomic and morphological diversity with the null expectations show little evidence of phylogenetic constraints; neither measure of morphological diversity exhibits an overall trend significantly different from that expected from sample size alone, based on a random draw across the entire phylogeny (Fig. 4). 



Fig. 3. Distribution of Strombus species (open circles) and Lambis species (closed circles) along the first three principal component axes. The three species illustrated in Fig. 1 are indicated; the circle for S. raninus in the lower panel is shaded. Note the large separation between Strombus and Lambis in morphospace.

\section{Discussion}

\subsection{Phylogenetic relationships within the genus Strombus}

Our molecular data provide the first estimate of relationships within the diverse group including Strombus s.l. and Lambis that is independent of morphological data. The slowly evolving nuclear gene $\mathrm{H} 3$ resolved some deep nodes, while the more rapidly evolving mitochondrial COI showed complementary strengths, recovering a tree with better resolution toward the branch tips. Slowly evolving nuclear genes typically provide less information than more rapidly evolving mitochondrial genes, but also tend to show less homoplasy (Clabaut et al., 2005). Poor resolution of deeper nodes by COI was not unexpected; synonymous substitutions appear to be near saturation for the most divergent taxa in our COI data (not shown), and substitution saturation at COI has been noted previously in mollusks (Marko, 2002). While the H3 and COI trees both have problems resolving relationships within Strombus and Lambis by themselves, they are statistically congruent and combine to provide a reasonable account of the phylogeny of these two genera, although the lack of resolution at some deeper nodes (e.g., the base of the IWP radiation) suggests a need for additional data from slowly evolving nuclear genes.

The phylogenetic analyses strongly supports the inclusion of Lambis within Strombus (s.l.); thus Strombus (s.l.) as
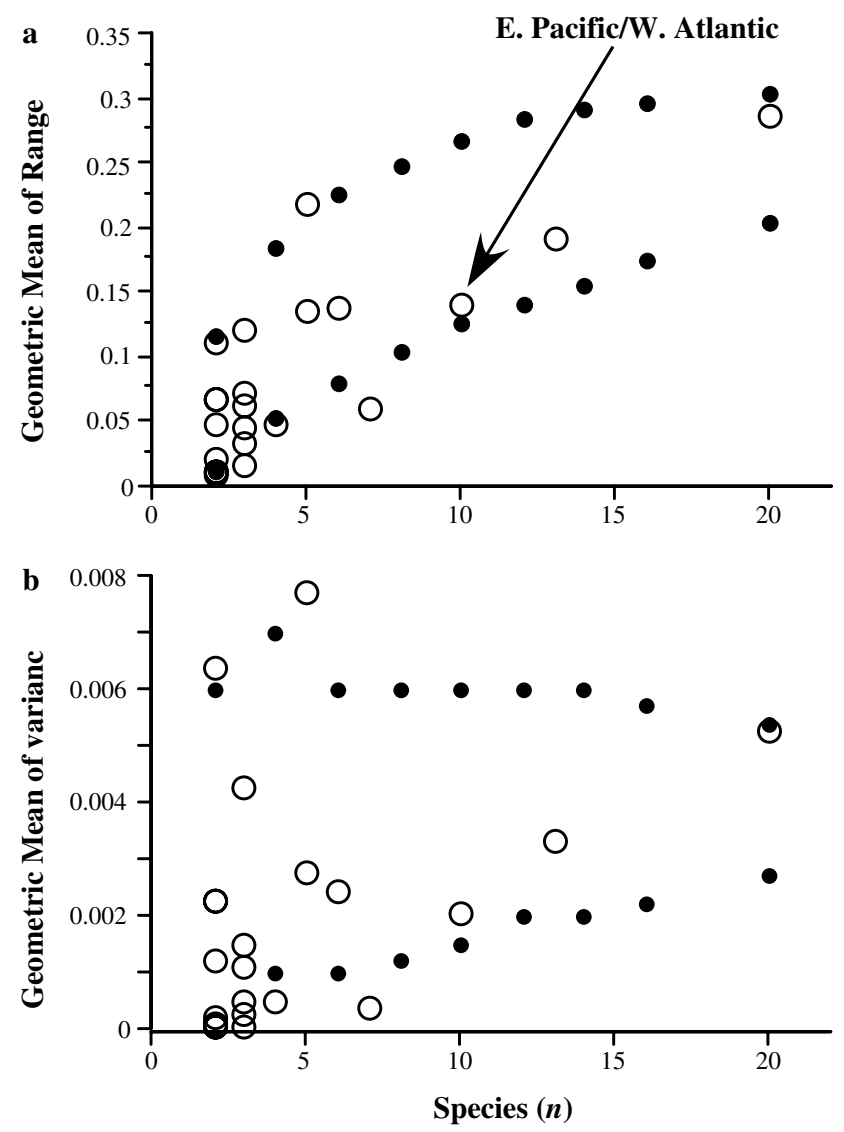

Fig. 4. The relationship between species richness and two different metrics of morphological diversity of subclades on the combined phylogenetic tree. (a) Geometric mean of the ranges of scores on the first six principal component axes and (b) geometric mean of the variance of scores on the first six PC axes. The arrow marks the subclade consisting of the Eastern Pacific and Western Atlantic species. The lines on each plot mark the $95 \%$ confidence interval for the expected relationship between the two variables when subclades are defined randomly (see text for details).

defined by Abbott (1961) is paraphyletic. Stone (2001) had suggested previously that Strombus (s.l.) was polyphyletic, with $L$. (Lambis) crocata falling outside an otherwise monophyletic Lambis (s.l.) we were unable to obtain tissue for $L$. crocata. Otherwise, our Lambis relationships are consistent with the systematics of Stone (2001), with L. (Lambis) truncata falling closer to $L$. (Harpago) chiragra than to L. (Lambis) lambis (Fig. 4), contrary to the subgeneric classification proposed by Abbott (1961). The suggestion that the IWP Tricornis may be the sister to Lambis (supported by BPP of 0.93, Fig. 2) is consistent with the digitated flared lip seen in some IWP Tricornis (e.g., S. taurus, Fig. 1) and their position in morphospace (Fig. 3b).

Our analyses also provide mixed support for the uniting of many strombid subgenera, including all EPA species, based on the possession of a glazed edge of the shell's outer lip (Kronenberg and Vermeij, 2002). Indo-West Pacific (sub)genera possessing this character include Euprotomus, Gibberulus, Tricornis, and Lambis (s.l.), all of which fall in a clade that includes a monophyletic EPA radiation (Fig. 2). However, one taxon lacking outer lip glazing (Conomurex) 
also falls into this clade with strong support, while others possessing a glazed outer lip (Laevistrombus, Labiostrombus) fall within the basal group of Indo-West Pacific taxa (Fig. 2). Although additional taxa and genetic markers would likely increase resolution within the basal IWP clade, our data suggest that lip glazing may be homoplasious among strombids.

Our taxon sampling is not sufficient to test for the monophyly of all the subgenera defined by Abbott $(1960,1961)$, but our results show that some of these are likely not monophyletic. For example, Tricornis includes Neotropical species that are apparently more closely related to Neotropical species in different subgenera than to their IndoWest Pacific consubgeners (Fig. 2). Kronenberg and Vermeij (2002) suggested that Lentigo as defined by Abbott (1960) was also polyphyletic based on morphological and paleontological criteria. We were unable to obtain COI sequence for Abbott's Lentigo type species (S. lentiginosus), but $\mathrm{H} 3$ sequences from that species suggest that it does not fall into the same clade as the EPA Lentigo species S. latus and $S$. granulatus (Appendix Fig. 1).

Relationships revealed by sequence data can be especially helpful when morphological characters are few and likely homoplasious, as in Canarium, which includes several species with small fusiform shells. Our data suggest that Canarium as defined by Abbott (1960) is not monophyletic, nor is Fusicanarium ( $S$. terebellatus, S. fragilis, S. dentatus, and S. fusiformis) of Romanga Manoja (1980a,b), a taxon of debatable status (Kronenberg and Vermeij, 2002). Only one of the Canarium species ( $S$. fragilis) moved to a new genus (Terestrombus) by Kronenberg and Vermeij (2002) was sampled here; it falls within the broader Canarium, and may not be closely related to either Gibberulus or Conomurex despite several similarities in shell shape noted by Kronenberg and Vermeij (2002) (Fig. 2). Few clades receive strong support however, despite sampling a reasonable 12 of Abbott's 17 nominal full extant species in Laevistrombus, Doxander, Labiostrombus, and Canarium. Future efforts to resolve species relationships among these species in these groups should explore additional sources of sequence data as well as more complete taxon sampling.

\subsection{Biogeography}

From a biogeographic perspective, our results strongly suggest a monophyletic Eastern Pacific/Atlantic clade derived from the IWP radiation, as suggested by Kronenberg and Vermeij (2002). Euprotomus, a subgenus restricted to the IWP, appears to be more closely related to the EPA clade than to other IWP subgenera (Fig. 2). This geographic pattern is different from those seen in some clades of other tropical marine gastropods. In Conus, IWP and EPA species often occur within the same clade, suggesting multiple radiations in both regions (Duda and Kohn, 2005). In Echinolittorina, IWP species belong to a single clade, with Eastern Pacific and Western Atlantic species being more basal (Williams and Reid, 2004). However, a pattern of Eastern Pacific or EPA monophyly nested within a larger IWP or circum-tropical species radiation has been noted previously in several reef fishes, including wrasses (Barber and Bellwood, 2005; Westneat and Alfaro, 2005), needlefish (Banford et al., 2004), and angelfish (Bellwood et al., 2004).

\subsection{Scaling of morphological and taxonomic diversity}

The relationship between taxonomic and morphological diversity seen here is qualitatively similar to that for all species of Indo-Pacific strombids analyzed by Roy et al. (2001), even though the previous study defined taxonomic diversity using species richness of geographic assemblages rather than richness of subclades used here. Geometric mean of the range of PC scores increases with species richness, suggesting that the volume of occupied morphospace increases as new species are added. This pattern is consistent with the idea that as richness increases, species tend to be added to the margins of morphospace (Ricklefs and Miles, 1994; Roy and Foote, 1997; Roy et al., 2001). In addition, the positive relationship between the geometric mean of variance of PC scores and species richness suggests that the internal packing of species in morphospace also changes as taxa are added. However, a positive relationship between species richness and the morphological diversity measures used here is also expected from sample size effects alone with subclades representing random groupings of species and we cannot reject such a sampling expectation (Fig. 4). Thus, although we think that the failure to reject the null hypothesis is largely a function of the small sample size of this study rather than a biological signal, these alternatives cannot be tested until a more complete phylogeny of strombid species is available. The results of the current study do suggest that overall phylogenetic constraint on the evolution of shell shape is at best fairly weak within the strombids, except perhaps within Lambis. This is further supported by the fact that the scaling of taxonomic and morphological diversity seen here is similar to that of Roy et al. (2001) who used geographic rather than monophyletic groupings.

\subsection{Caveats}

Inferences about diversification and patterns of morphological evolution using molecular phylogenies cannot incorporate information about past extinctions. Hence analyses such as those presented here assume that extinction is not biased in terms of morphology or clade membership. If, on the other hand, past extinctions are morphologically, phylogenetically or ecologically selective, then conclusions about rates and patterns of evolution (morphological or otherwise) based solely on molecular phylogenies may not be accurate. For strombid gastropods, there is some evidence that past extinctions were morphologically selective (Freiheit and Geary, 2001) but the effect of such selectivity on the results presented here is unknown at present. 
Secondly, at this point we cannot rule out the possibility that the weak phylogenetic constraint on the evolution of shell shape seen here is, at least partly, a reflection of incomplete taxon sampling; a more complete sampling of species within individual lineages of strombids could potentially reinforce inter-clade differences and hence reveal stronger phylogenetic constraints on morphological evolution of this group. Quantitative tests of these possibilities would require integrating sequence information from more species of living strombids with the excellent fossil record of this group.

\section{Acknowledgments}

We thank the many people who helped us obtain tissue samples, including J. Slapcinsky at the Florida Museum of Natural History, M. Harasewych at the Smithsonian, G. Rosenberg at the Academy of Natural Sciences of Philadelphia, the Delaware Museum of Natural History, S. Merino at the Instituto Nacional de Desenvolvimento das Pescas in Cabo Verde, P. Marko, J. Schulz, and especially E. Garcia and K. Hutsell. P. Arbour-Reiley helped with laboratory work. M. Hafner and L. Anderson provided constructive comments on early drafts of the manuscript. This work was funded in part by an NSF grant (DEB-0075382) to MEH.

\section{Appendix A. Supplementary data}

Supplementary data associated with this article can be found, in the online version, at doi:10.1016/ j.ympev.2006.05.027.

\section{References}

Abbott, R.T., 1960. The genus Strombus in the Indo-Pacific. Indo-Pac. Moll. 1, 33-146.

Abbott, R.T., 1961. The genus Lambis in the Indo-Pacific. Indo-Pac. Moll. $1,147-174$

Banford, H.M., Bermingham, E., Collette, B.B., 2004. Molecular phylogenetics and biogeography of transisthmian and amphi-Atlantic needlefishes (Belonidae: Strongylura and Tylosurus): perspectives on New World marine speciation. Mol. Phylogenet. Evol. 31, 833-851.

Barber, P.H., Bellwood, D.R., 2005. Biodiversity hotspots: evolutionary origins of biodiversity in wrasses (Halichoeres: Labridae) in the IndoPacific and New World tropics. Mol. Phylogenet. Evol. 35, 235-253.

Bellwood, D.R., van Herwerden, L., Konow, N., 2004. Evolution and biogeography of marine angelfishes (Pisces: Pomacanthidae). Mol. Phylogenet. Evol. 33, 140-155.

Chase, M.R., Etter, R.J., Rex, M.A., Quattro, J.M., 1998. Extraction and amplification of mitochondrial DNA from formalin-fixed deep-sea mollusks. Biotechniques 24, 243-247.

Clabaut, C., Salzburger, W., Meyer, A., 2005. Comparative phylogenetic analyses of the adaptive radiation of the Lake Tanganyika cichlid fish: nuclear sequences are less homoplasious but are also less informative than mitochondrial DNA. J. Mol. Evol. 61, 666-681.

Colgan, D.J., Mclauchlan, A., Wilson, G.D.F., Livingston, S., Macaranas, J., Edgecombe, G.D., Cassis, G., Gray, M.R., 1998. Molecular phylogenetics of the Arthropoda: relationships based on histone $\mathrm{H}$ and $\mathrm{U} 2$ snRNA DNA sequences. Aust. J. Zool. 46, 419-437.

Cunningham, C.W., 1997. Can three incongruence tests predict when data should be combined? Mol. Biol. Evol. 14, 733-740.
DeBry, R.W., Marzluff, W.F., 1994. Selection on silent sites in the rodent H3 histone gene family. Genetics 138, 191-202.

Duda, T.F.J., Kohn, A.J., 2005. Species-level phylogeography and evolutionary history of the hyperdiverse marine gastropod genus Conus. Mol. Phylogenet. Evol. 34, 257-272.

Folmer, O., Black, M., Hoeh, W., Lutz, R., Vrijenhoek, R., 1994. DNA primers for amplification of mitochondrial cytochrome $\mathrm{c}$ oxidase subunit I from diverse metazoan invertebrates. Mol. Mar. Biol. Biotechnol. 3, 294-299.

Foote, M., 1995. Morphological diversification of Paleozoic crinoids. Paleobiology 21, 273-299.

Foote, M., 1997. The evolution of morphological diversity. Ann. Rev. Ecol. Syst 28, 129-152.

Freiheit, J., Geary, D.H., 2001. Species-level evolutionary patterns in Neogene strombids from the Dominican Republic. Paleobios(No.2 Suppl.), 54

Harmon, L.J., Schulte II, J.A., Larson, A., Losos, J.B., 2003. Tempo and mode of evolutionary radiation in iguanian lizards. Science 301, 961-964.

Harper, J.L., Hawksworth, D.L., 1994. Biodiversity: measurement and estimation. Phil. Trans. Roy. Soc. Lond.f B 345, 5-12.

Huelsenbeck, J.P., Crandall, K.A., 1997. Phylogeny estimation and hypothesis testing using maximum likelihood. Ann. Rev. Ecol. Syst 28, $437-$ 466.

Huelsenbeck, J.P., Ronquist, R., 2001. MRBAYES: Bayesian inference of phylogeny. Bioinformatics 17, 754-755.

Hulsey, C.D., Wainwright, P.C., 2002. Projecting mechanics into morphospace: disparity in the feeding system of labrid fishes. P. Roy. Soc. Lond. B 269, 317-326.

Isaev, M.A., 1995. EFA Win. Available at <http://life.bio.sunnysb.edu/ $\operatorname{morph} />$.

Isaev, M.A., Denisova, L.N., 1995. The computer programs for shape analysis of plant leaves. In: Proc. Math. Comp. Edu. Intl. Conf. Pushchino, Russia.

Kronenberg, G.C., 1993. On the identity of Lambis wheelwrighti Greene, 1978 and L. arachnoides Shikama, 1971. Vita Marina 42, 41-56.

Kronenberg, G.C., 1998. Revision of Euprotomus Gill, 1870. 1. The systematic position of Strombus listeri Gray, 1852. Vita Marina 45, 1-6.

Kronenberg, G.C., 1999. Revision of Euprotomus Gill, 1870. 2. On the identity of Strombus hirasei Kuroda, 1942 (Gastropoda Prosobranchia: Strombidae). The Festivus 30, 63-66.

Kronenberg, G.C., Vermeij, G.J., 2002. Terestrombus and Tridentarius, new genera of Indo-Pacific Strombidae (Gastropoda), with comments on the included taxa and on shell characters in Strombidae. Vita Malacologica $1,49-54$.

Leaché, A.D., Reeder, T.W., 2002. Molecular systematics of the eastern fence lizard (Sceloporus undulatus): a comparison of parsimony, likelihood, and Bayesian approaches. Syst. Biol. 51, 44-68.

Marko, P.B., 2002. Fossil calibration of molecular clocks and the divergence times of geminate species pairs separated by the Isthmus of Panama. Mol. Biol. Evol. 19, 2005-2021.

McClain, C.R., Johnson, N.A., Rex, M.A., 2004. Morphological disparity as a biodiversity metric in lower bathyal and abyssal gastropod assemblages. Evolution 58, 338-348.

Mienis, H.K., 1971. Revision of Strombus (Canarium) mutabilis ochroglottis Abbott (Gstropoda: Strombidae). Arch. Moll. 101, 301-304.

Nylander J.A.A., 2002. MrModeltest v1.0b. Dept of Systematic Zoology, Uppsala University. <http://www.ebc.uu.se/systzoo/staff/ nylander.html>

Posada, D., Crandall, K.A., 1998. Modeltest: testing the model of DNA substitution. Bioinformatics 14, 817-818.

Purvis, A., Hector, A., 2000. Getting the measure of biodiversity. Nature 405, 212-219.

Ricklefs, R.E., 2004. Cladogenesis and morphological diversification in passerine birds. Nature 430, 338-341.

Ricklefs, R.E., 2005. Small clades at the periphery of passerine morphological space. Am. Nat. 165, 651-659.

Ricklefs, R.E., Miles, D.B., 1994. Ecological and evolutionary inferences from morphology: an ecological perspective. In: Wainwright, P.C., 
Reilly, S.M. (Eds.), Ecological Morphology. University of Chicago Press, Chicago, pp. 13-41.

Rohlf, F.J., Ferson, S., 1992. Elliptic Fourier analysis. <http://life.bio.sunnysb.edu/morph/>.

Romanga Manoja, E., 1980a. Superfamily Stromboidea. Part VI. Subgenus Canarium. La Conchiglia 18 (12-16), 130-131.

Romanga Manoja, E., 1980b. Superfamily Stromboidea. Part VIII. Subgenus Canarium. La Conchiglia 136-17, 3-5.

Rooney, A.P., Piontkivska, H., Nei, M., 2002. Molecular evolution of the nontandemly repeated genes of the histone 3 multigene family. Mol. Biol. Evol. 19, 68-75.

Roy, K., 1996. The roles of mass extinction and biotic interaction in largescale replacements? A reexamination using the fossil record of stromboiden gastropods. Paleobiology 22, 436-452.

Roy, K., Foote, M., 1997. Morphological approaches to measuring biodiversity. Trends Ecol. Evol. 12, 277-281.

Roy, K., Balch, D.P., Hellberg, M.E., 2001. Spatial patterns of morphological diversity across the Indo-Pacific: analyses using strombid gastropods. P. Roy. Soc. Lond. B 268, 2503-2508.

Savazzi, E., 1991. Constructional morphology of strombid gastropods. Lethaia 24, 311-332.

Stone, J.R., 2001. A cladistic analysis of species of Lambis (Gastropods: Strombidae). Nautilus 115, 90-98.

Swofford, D.L., 2001. PAUP: phylogenetic analysis using parsimony (and other methods). Version 4.0. Sinauer Assoc., Sunderland, MA.

Thatcher, T.H., Gorovsky, M.A., 1994. Phylogenetic analysis of the core histones H2A, H2B, H3, and H4. Nucleic Acids Res. 22, $174-179$
Toonen, R.J., 1997. Microsatellites for ecologists: non-radioactive isolation and amplification protocols for microsatellite markers. Unpublished manuscript, Ver. 1, ftp://biogeek.ucdavis.edu/Msats/.

Vermeij, G.J., 1978. Biogeography and Adaptation: Patterns of Marine Life. Harvard University Press, Cambridge, MA.

Vermeij, G.J., 1987. Evolution and Escalation: An Ecological History of Life. Princeton University Press, Princeton.

Vermeij, G.J., Signor, P.W., 1992. The geographic, taxonomic and temporal distribution of determinate growth in marine gastropods. Biol. J. Linn. Soc. 47, 233-247.

Wagner, P.J., 1995. Testing evolutionary constraint hypotheses with early Paleozoic gastropods. Paleobiology 21, 248-272.

Wagner, P.J., 1996. Patterns of morphological diversification during the initial radiation of the 'Archaeogastropoda'. In: Taylor, J.D. (Ed.), Origin and Evolutionary Radiation of the Mollusca. Oxford University Press, Oxford, pp. 161-169.

Westneat, M.W., Alfaro, M.E., 2005. Phylogenetic relationships and evolutionary history of the reef fish family Labridae. Mol. Phylogenet. Evol. 36, 370-390.

Williams, P.H., Gaston, K.J., Humphries, C.J., 1994. Do conservationists and molecular biologists value differences between organisms in the same way? Biodiver. Lett. 2, 67-78.

Williams, S.T., Reid, D.G., 2004. Speciation and diversity on tropical rocky shores: a global phylogeny of snails of the genus Echinolittorina. Evolution 58, 2227-2251.

Wilson, A.B., Glaubrecht, M., Meyer, A., 2004. Ancient lakes as evolutionary reservoirs: evidence from the thalassoid gastropods of Lake Tanganyika. P. Roy. Soc. Lond. B 271, 529-536. 